\title{
LA SECCIÓN FEMENINA EN PERSPECTIVA. HISTORIAS Y OTROS RELATOS SOBRE LAS MUJERES DE FALANGE
}

\author{
SECCIÓN FEMENINA IN PERSPECTIVE. \\ HISTORY AND OTHER NARRATIVES ABOUT FALANGIST WOMEN
}

Begoña Barrera*

Universidad de Sevilla, España

\begin{abstract}
RESUMEN: La bibliografía dedicada al estudio de la Sección Femenina de FET-JONS cuenta ya con cuatro décadas de recorrido, tiempo durante el que ha ido participando de distintas tendencias historiográficas. Partiendo de esta premisa, el propósito del presente ensayo es explorar las principales aportaciones sobre el falangismo femenino atendiendo tanto a la singularidad de sus diferentes análisis como al contexto epistemológico en el que estos se han desarrollado. Con este objetivo, la primera parte analiza transversalmente la polémica que ha mantenido más activa la atención sobre las mujeres del falangismo español, relativa a la contradicción entre el paradigma de feminidad que la élite de la Sección Femenina personificaba y el modelo que la misma imponía al resto de españolas, mientras que la segunda ofrece una revisión de las formas de escribir la historia de la Sección Femenina que resultan más pertinentes en la actualidad. Esta doble vía de estudio permite clarificar la evolución de los interrogantes que han venido guiando la investigación sobre la organización hasta hoy.
\end{abstract}

PALABRAS CLAVE: Sección Femenina de FET-JONS, género, Falange, Franquismo.

ABSTRACT: The bibliography devoted to the study of Seccion Femenina of FET-JONS has already four decades of developing, a time that has allowed it to take part in some of the most relevant historiographical trends. On the basis of that postulate, the purpose of this essay is to explore the main contributions about female falangism attending both the singularity of each work and the epistemological context in which it has been produced. With this aim, the first part analyses transversally the controversy that has hold the attention of specialists in the $S F$, the one related to the contradiction between the female paradigm embodied by the women of the organization and the female ideal that they imposed to Spanish women. The second part proposes a review of the current perspectives used to write the history of Sección Femenina. This two-ways approach allows to clarifying which are the main questions that lead today the researches on this organization.

KEYWORDS: Sección Femenina de FET-JONS, gender, Falange, Franquism.

* Correspondencia a: Begoña Barrera. Departamento de Historia Contemporánea. Facultad de Geografía e Historia. Universidad de Sevilla. Calle María de Padilla, s/n (41004 Sevilla, España) - begobarlop@gmail.com - https://orcid. org/0000-0001-5574-8479

Cómo citar: Barrera, Begoña (2020). «La Sección Femenina en perspectiva. Historias y otros relatos sobre las mujeres de Falange»; Historia Contemporánea, 62, 265-295. (https://doi.org/10.1387/hc.20029).

Recibido: 28 junio 2018; aceptado: 15 febrero, 2019.

ISSN 1130-2402 - eISSN 2340-0277 / (C) 2020 UPV/EHU

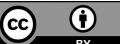

Esta obra está bajo una licencia

Creative Commons Atribución 4.0 Internacional 
En el inicio de la década de los años ochenta, apenas unos años después de la disolución de la Sección Femenina de FET-JONS (en adelante, SF), el interés por la historia de esta organización comenzó a despuntar en los círculos académicos españoles. Desde las ciencias políticas primero, y muy pronto también desde la historiografía, un número creciente de investigadoras empezó a indagar en la compleja estructura femenina de Falange con el propósito de explicar los orígenes y el desarrollo del sistema de adoctrinamiento bajo el que tanto ellas como la generación de sus madres habían vivido. En el ámbito historiográfico, buena parte de los trabajos realizados durante los años ochenta y noventa por esta primera generación de estudiosas se adscribieron a la órbita de una historia social centrada en la interpretación del falangismo femenino como fenómeno colectivo cuantificable, datable y sujeto a unas estructuras aprehensibles que explicaban su naturaleza.

Si bien es verdad que el peso de la historia social en España fue determinante para la orientación de aquellos trabajos, también es necesario señalar que algunas hispanistas extranjeras, principalmente francesas, inglesas y estadounidenses, fueron pioneras en la aplicación del enfoque culturalista al estudio de la SF en fechas tan tempranas como 1979. Para que esta perspectiva fuera mayoritaria en España, o al menos contara con una amplia representación, hubo que esperar al cambio de siglo. A partir del año 2000 aproximadamente, un nuevo conjunto de historiadores que aquí se ha considerado como la segunda generación se aupará sobre las aportaciones de las primeras investigadoras españolas y sobre las visiones renovadas de los estudios extranjeros para impulsar trabajos más refinados teóricamente y sobre todo mucho más plurales en sus perspectivas historiográficas. En lo que respecta a estos últimos, no existe una tendencia común más allá de una fructífera multiplicidad de posiciones que van desde el estudio trasnacional a lo local, pasando por la biografía, y que en ocasiones se nutren de una perspectiva cultural de lo político. Por ello, y teniendo en cuenta la dificultad de sintetizar todas las tendencias generales de más de cuatro décadas de investigación, las siguientes páginas trazan un recorrido por las principales aportaciones sobre el falangismo femenino atendiendo tanto a la singularidad de cada trabajo sobre esta cuestión, como al contexto historiográfico en el que se ha desarrollado. Su propósito es configurar una cartografía en la que se pongan a dialogar las ideas de los autores principales, tratando de clarificar algunos de los conceptos que subyacen a cada una de las propuestas citadas. 


\section{La genealogía de un debate historiográfico}

Cualquier revisión de la historiografía sobre el falangismo femenino debe comenzar citando el trabajo pionero de María Teresa Gallego Méndez, Mujer, Falange y Franquismo, leído como tesis doctoral en 1982 y publicado al año siguiente, y que constituye aún hoy la base indispensable para todos los estudios sobre la SF. ${ }^{1}$ Una de las principales ideas defendidas en sus páginas se refiere a la sumisión que la organización femenina experimentó respecto a Falange y, en un sentido amplio, a todo el aparato del régimen franquista. Para la autora, esta actitud sería la prolongación lógica y coherente del mismo mensaje de subalternidad que la propia organización había intentado transmitir al resto de mujeres españolas, al menos, hasta 1945, fecha en la que concluye el estudio de Gallego. Muy deudor de la perspectiva de género introducida en las investigaciones sociológicas de los años ochenta en España, cabe destacar, aunque sea solo a modo de cita, su empleo de la categoría «patriarcado» en referencia a la opresión sistemática ejercida por el régimen, ampliando de esta forma, y de un modo a todas luces innovador, la comprensión de las dinámicas de poder-resistencia durante el franquismo. ${ }^{2}$

Si bien es evidente que la sumisión al partido, y luego al Movimiento, es una de las ideas más destacadas del trabajo de Gallego y, por ende, más subrayada por la historiografía, es necesario también recuperar otras apreciaciones de la autora menos tenidas en cuenta en estudios posteriores. Así, afirmaba que, «con la perspectiva del tiempo transcurrido, parece evidenciarse una clara contradicción entre el modelo de mujer propuesto por la SF para todas las mujeres españolas y el desarrollo por sus mandos y jerarquías». De esta forma, Gallego incidía en la ambivalencia del mensaje de las falangistas, que mientras promovía para las miembros de la organización un estilo de vida más parecido al de una «milicia», exigiéndoles total dedicación y sacrificio y, por ende, un estado de soltería,

1 Gallego Méndez, 1983.

${ }^{2}$ Es altamente significativo que la Sección Femenina cobre relevancia como tema de estudio en el contexto universitario de principios de los años ochenta, cuando la investigación feminista empieza a abrirse camino en los espacios académicos y a hacerse presente a través de la creación de grupos de estudio interdisciplinares sobre la mujer. Véanse al respecto los estudios recopilados en Pérez Cantó et al., 2005. Esto se produce, además, en paralelo a la aparición de las primeras monografías sobre la historia de las mujeres en la Italia fascista o en la Alemania nazi, Morant, 2018, p. 13. 
defendía como único modelo de mujer legítimo aquel de «madre hacendosa, abnegada y servicial, adornada de todos los valores tradicionales que el patriarcado creó para ella a lo largo de los siglos». ${ }^{3}$ Si bien tal paradoja no aparece del todo desarrollada en esta obra - como sí lo hará en estudios posteriores de otros autores -, no cabe duda de que la temprana aportación de Gallego no puede ser considerada solo por su defensa, hoy muy cuestionada, de la pasividad y sumisión de las mujeres de la SF a los poderes políticos franquistas. La inclusión de afirmaciones como la citada arriba, o como la que de que «resulta poco alentador el intento de averiguar, con precisión, cuál era el modelo de mujer nacionalsindicalista, puesto que de ella se dijeron cosas sorprendentes, contradictorias e, incluso, ofensivas», han de ser tenidas en cuenta como las primeras evidencias, tal vez a la par intuitivas y empíricas, de una problemática que necesitaba ser trabajada a fondo en el futuro. ${ }^{4}$

Pocos años después, en 1985, Rosario Sánchez López comenzaba una tesis de licenciatura dedicada a la organización falangista, publicada ya en 1990, en la que recogería el testigo de Gallego, tratando de abarcar esta vez toda la trayectoria de la SF hasta 1977. Aunque en sus presupuestos fundamentales este trabajo incidía en la función de las falangistas como correa de transmisión del discurso patriarcal del régimen, de nuevo Sánchez López volvía a toparse con una aparente dificultad al percibir la distancia que existía entre un modelo de mujer que la SF pretendía inculcar a las españolas (y que aparecía en sus términos básicos muy claros: maternal, dócil, religiosa, etc.) y el ideal femenino, el «estilo» que ellas mismas intentaban construir como mujeres y falangistas. Así, la autora reconocía que «si tuviéramos que designar con una sola palabra nuestra estimación acerca de la noción de estilo en los discursos emanados de Sección, ésta sólo podría ser la de paradoja». ${ }^{5}$ La confusión entre lo que la organización predicaba para el resto de mujeres - según estas autoras, la obediencia y subyugación sin cuartel-, y los atributos que reservaban para definirse a ellas mismas como organización femenina dirigente, aparecía ya en estas primeras obras dedicadas a la SF. Y aunque no se formulase explícitamente como un problema u objeto de estudio, sentaba precedente para un debate que se seguiría perfilando en las siguientes décadas.

\footnotetext{
3 Gallego Méndez, 1983,pp. 106 y 107.

4 Gallego Méndez, 1983, p. 182.

5 Sánchez López, 1990, p. 75.
} 
Lo cierto es que para que ello ocurriera fue indispensable que el interés por la organización femenina de Falange, así como por la historia de las mujeres de - o cercanas a- las derechas del siglo XX, cobrara un nuevo impulso. La misma Sánchez López publicaba en 1993 un artículo de título elocuente: «Sección Femenina, una institución en busca de investigador. Análisis crítico de la bibliografía disponible». En su diagnóstico de principios de los años noventa, la autora atestiguaba «la situación ensombrecida» en la que se encontraba «una de las instituciones de más larga pervivencia del régimen franquista» y pretendía recoger sintética y esquemáticamente todas las aportaciones que, desde una perspectiva u otra, hubieran tratado, o al menos mencionado, la existencia de la SF. Finalmente, la autora señalaba tres vías posibles de análisis que podrían ser desarrolladas en investigaciones futuras y que, de hecho, resumían en buena medida los derroteros que aquellas han tomado: la profundización en la ideología propia de la organización, el margen de actuación política real que esta tuvo y su dimensión sociológica (origen social, alcance cuantitativo de la afiliación y valoración de su impacto mediante el empleo de fuentes orales). ${ }^{6}$

Uno de los estudios reseñados por Sánchez López en aquel texto fue el de Marie Aline Barrachina Morón, quien, a partir de la elaboración de su tesis doctoral en 1979, había comenzado a investigar a la organización falangista desde un enfoque esencialmente interesado por el análisis del discurso. ${ }^{7}$ En este sentido, y para la genealogía del debate que aquí nos ocupa, resulta esencial el texto publicado por Barrachina con el título «Ideal de la Mujer Falangista. Ideal Falangista de la Mujer», donde ya se enunciaba la paradoja a la que se enfrentaría cualquier estudio que abordase la SF. ${ }^{8}$ Al proponer esta disyuntiva, Barrachina señalaba la doble dirección a la que apuntaban los discursos de la organización falangista: por un lado, estos se dirigían a definir las tareas y las pautas de conducta de una élite femenina constituida por las delegadas provinciales y, en menor medida, por las delegadas locales, quienes representaban el modelo oficial

${ }^{6}$ Sánchez López, 1993, pp. 141-154. Este artículo recogía la información vertida sobre la SF en: 1) los estudios sobre Falange, 2) las obras dedicadas a los estudios de la mujer y 3) las obras centradas en el análisis de la institución. El minucioso rastreo bibliográfico que Sánchez López hizo en los dos primeros puntos me exime de abordar tal tarea, que además supondría una importante desviación del objetivo que se propone este ensayo.

7 Barrachina Morón, 1979.

8 Barrachina Morón, 1991, pp. 211-217. 
de «mujer falangista»; por otro, esta misma alta jerarquía de la organización difundiría el ideal de mujer para un Estado nacional-sindicalista, una identidad femenina construida sobre la base innegociable de la domesticidad y la maternidad y, por tanto, de límites mucho más restrictivos que los de aquella élite de mujeres falangistas que portaba el discurso.

El doble modelo propuesto por Barrachina abrió las puestas a sendas vías de análisis que en los años posteriores fueron paralelas y se construyeron atendiendo a su reciprocidad. De un lado, quedaba claro que sería fundamental ahondar en las identidades de las élites femeninas nacionalsindicalistas dentro del marco de desmovilización social general de los años cuarenta, a fin de averiguar de qué modo habían conseguido no solo tener un papel activo de facto en la construcción del nuevo Estado mediante el acceso a puestos burocráticos, sino también cómo se las habían arreglado para legitimar una identidad femenina falangista propia en el seno de una organización que exaltaba lo viril en tanto que elemento inherente a su carácter ascético y militar. De otro, parecía necesario ahondar en el análisis de los discursos promovidos por las altas jerarquías y dirigidos a la población femenina, tratando de cotejar su voluntad dirigista con la realidad cotidiana de las mujeres que conformaron sus experiencias bajo el tutelaje discursivo de la organización. Finalmente, estos dos ámbitos necesitarían ser confrontados a fin de dilucidar mediante qué estrategias la SF pudo trabajar, durante más de cuarenta años, para que las españolas se circunscribieran a un modelo de mujer que, aunque las falangistas definieran como «auténtico»y «esencial», ellas mismas estaban muy lejos de representar.

Así, esta doble vía de análisis enlazó con las propuestas de investigación sobre la SF desarrolladas en los últimos noventa y a partir del cambio de siglo. En este sentido, ha sido muy explorada la línea de estudio sobre las posibilidades de agencia de estas mujeres dentro del aparato del régimen; el propósito que esta orientación tuvo fue, en palabras de Ángela Cenarro, averiguar «cuál fue la aportación de las mujeres fascistas a la construcción de regímenes dictatoriales y, por tanto, tratarlas como sujetos históricos que tomaron decisiones en el contexto que les tocó vivir y en el marco de una determinada cultura política, la del fascismo». ${ }^{9}$

Efectivamente la imagen estereotipada de las falangistas como mujeres a la vez represoras y reprimidas, subordinadas a Franco y a sus cama-

9 Cenarro, 2011, p. 230. 
radas de partido exactamente igual que ellas subordinaban y controlaban al resto de las mujeres españolas, fue cuestionada por estudios como el de Victoria Lorée Enders, «Problematic Portraits: The Ambiguous Historical role of the Sección Femenina of the Falange». ${ }^{10}$ En su opinión, la historia de la SF había sido interpretada a partir dos posiciones contrarias. De un lado, desde la visión negativa aportada por las investigadoras ocupadas en este tema desde los tempranos años ochenta, en el clima intelectual progresista arriba señalado. Para Enders, autoras como Gallego Méndez y Sánchez López habían elaborado sus teorías partiendo de un contexto historiográfico que privilegiaba las experiencias de las mujeres vinculadas a las izquierdas o a posiciones liberales, a las que sí reconocían cierta agencia en los procesos políticos del siglo XX, en oposición a las mujeres falangistas, a quienes acusaban de haber trabajado para un régimen patriarcal en beneficio de la represión y la sumisión femenina, y en perjuicio de sus derechos como individuos. Por otro lado, frente a esta lectura, se situaba la interpretación de las mujeres que formaron parte de la organización, a las que Enders entrevistó entre 1989 y 1991, y en cuyos testimonios orales se basaba para caracterizar la postura «de la derecha». Desde su punto de vista, la labor de estas falangistas al frente de la SF debe ser considerada «progresista», en tanto que estuvo dedicada a mejorar las condiciones vitales de las mujeres y los niños españoles durante más de cuarenta años. La hostilidad de la que Enders denominaba «la postura de la izquierda» no era comprensible para aquellas, puesto que su interpretación de sí mismas era la de un grupo de mujeres revolucionarias, como lo fue su patrona Santa Teresa, que habían luchado por implantar el ideal de justicia social nacionalsindicalista.

En opinión de la autora, bajo esta situación de incomprensión entre discursos mutuamente excluyentes residía el problema de la agencia histórica o, en sus propias palabras, de «la incapacidad para reconciliar la agencia histórica de estas mujeres con su adscripción a los valores tradicionalistas y fascistas». Desde posturas «antagonistas» a la SF se habría negado a las falangistas la posibilidad de ser consideradas de otro modo diferente al de meros peones del régimen, obviando el hecho de que «las mujeres de Falange no eran solo mujeres tradicionales: las categorías clásicas del análisis histórico no funcionan cuando se las aplica a la expe1992.

${ }^{10}$ Lorée Enders, 1999. Estas cuestiones ya aparecían implícitas en Lorée Enders, 
riencia de la SF». ${ }^{11}$ Por consiguiente, la historia de las falangistas no solo tendría que desprenderse de un marco interpretativo binario «izquierdaderecha» o «izquierda-contra-derecha», sino que debería reconocer la capacidad de aquellas, en tanto que agentes, y por tanto conformadores del proceso histórico en el que viven, y aplicar consecuentemente categorías de análisis nuevas que permitieran profundizar en sus identidades específicas.

También se preguntó por la agencia histórica y por la adecuación de las categorías de sumisión y abnegación a las falangistas Inmaculada Blasco Herranz en Armas femeninas para la contrarrevolución: la Sección Femenina en Aragón (1936-1950). ${ }^{12}$ La determinación con la que actuaron las jerarquías de la organización fue puesta de manifiesto por este estudio de 1999, que dedicaba un apartado a demostrar la firmeza con la que la SF confrontó las órdenes de la jerarquía masculina que no consideraba adecuadas. ${ }^{13}$ Poco después, en otro texto, Blasco Herranz abundaba en esta tesis al afirmar que «uno de los aspectos más sugestivos de las trayectorias vitales de las mujeres de la SF era sin duda la contradicción que se generó entre la ideología y el discurso que se proponían inculcar al resto de la población femenina, y su propia práctica de vida». ${ }^{14}$

En estas mismas fechas, Rosario Coca Hernando publicaba su artículo «Towards a New Image of Women under Franco: the role of Sección Femenina», donde no solo partía de la tesis de la dualidad identitaria élites-masas en la SF, sino que también ofrecía una posible explicación cronológica a este fenómeno que sería recuperada habitualmente en el debate historiográfico posterior. ${ }^{15}$ Para esta autora, la década de 1960 había marcado una clara transformación en los modelos de mujer española propuestos por la SF: hasta esta fecha, el discurso acerca de la mujer gravitaba sobre principios conservadores, mientras que a partir del proceso de liberalización económica y modernización durante los años sesenta la organización revisó y reconstruyó su modelo de mujer con los atributos de la «mujer moderna». Según esta visión, fue la insuficiencia de los roles de «perfecta casada» y de «ángel del hogar» la que habría llevado a la SF a buscar nuevas fórmulas mediante las que adaptarse a los cambios socia-

\footnotetext{
11 Lorée Enders, 1999, p. 389-390.

12 Blasco Herranz, 1999.

13 Blasco Herranz, 1999, pp. 148-149.

14 Blasco Herranz, 2000, p. 264.

15 Coca Hernando, 1998, pp. 5-13.
} 
les y, de esta forma, continuar ostentando la primacía en la elaboración de las identidades femeninas. Sintéticamente, se puede afirmar que el estudio de Coca Hernando trataba de reconciliar la contradicción entre el «modelo falangista de mujer» y el «modelo de mujer falangista» proponiendo la tesis de un acercamiento del primero hacia el segundo conforme la modernización de los roles femeninos se fue haciendo más inevitable y las falangistas tuvieron que reconocerles a las demás mujeres unos atributos que antes eran patrimonio exclusivo de las élites de la organización.

En 1999, Kathleen Richmond leía en la Universidad de Southampton su tesis The Yoke of Isabella: the Women's Section of the Spanish Falange 1934-1959, publicada en español en 2003 con el título Las mujeres en el fascismo español. La Sección Femenina de la Falange, 1934-1959.16 Aunque el periodo que abarca el estudio no le permitió a su autora incorporar la posición de investigadoras como Coca Hernando, este trabajo recogía en parte el testigo de las investigaciones anteriores y mostraba la centralidad del debate en torno a la contradicción entre modo de vida y discurso de la SF. «Ambivalencia», «paradoja», «incoherencia»y «contradicción» son solo algunos de los términos con los que Richmond se refería a esta cuestión en las páginas de su estudio, y probablemente el hacerlo evidente desde un análisis amplio y bien documentado fuera uno de sus mayores logros. Continuas afirmaciones como «el estilo de vida de la élite de la SF tenía poco en común con el del «ángel del hogar»», «el contraste entre los mandos y la naturaleza reaccionaria del mensaje predicado por ellas fue siempre una paradoja» o «existía una contradicción esencial entre la defensa de las funciones tradicionales del sexo femenino propugnada por la SF en el caso de las mujeres no afiliadas y las cualidades personales y el estilo de vida exigidos a las portadoras de este mensaje» reflejaban este punto de vista. ${ }^{17}$

En continuidad con lo que tanto Enders como Blasco Herranz ya habían apuntado, Richmond concluía que «la evolución de la SF había sido contradictoria por su dependencia externa de los varones y, no obstante, su autosuficiencia real», un hecho que hacía a los altos mandos de la organización «destacar en una sociedad de predominio masculino como las únicas mujeres con autoridad moral y política». ${ }^{18} \mathrm{La}$ importancia que el trabajo de Richmond concedió a los esfuerzos realizados por la élite de

\footnotetext{
16 Richmond, 1999, 2003.

17 Richmond, 2003, pp. 39 y 43.

18 Richmond, 2003, pp. 219-220.
} 
la SF para lograr un lugar propio dentro de aquel régimen masculinizado fue, a todas luces, un dinamizador para posteriores investigaciones sobre el alto círculo falangista femenino. No obstante, tampoco habría que perder de vista que Richmond mantuvo una visión de lo que venimos llamado «agencia» muy centrada en las luchas concretas de Pilar Primo de Rivera. Si bien se reconocía la trascendencia de la capacidad estratégica de la Delegada Nacional en momentos clave como la Unificación de 1937 o la aprobación de la Ley de Sucesión de 1947, también se echa muy falta un análisis, o cuanto menos una mención, al papel de otras dirigentes que también participaron activamente en el ingenio de maniobras para mantener a la SF en la centralidad de la vida social del régimen. ${ }^{19}$

En cualquier caso, recapitulando lo visto hasta aquí, se puede percibir cómo en la bibliografía de los años noventa y principios de siglo se afianzaban dos premisas que se convertirían en constantes para las investigaciones posteriores: en primer lugar, la lectura de la SF como un grupo de mujeres absolutamente sumisas a los poderes masculinos quedaba sustituida por una interpretación generalizada que las reconocía como participantes y moldeadoras de su propio presente. En segundo lugar, se hacía más firme la necesidad de dar respuesta al dilema de la «dualidad» o la «contradicción» entre los modos de vida de las élites de la SF y los del resto de españolas, incluidas las propias bases de su misma organización.

Así se aprecia en las conclusiones que investigadoras como Helen Graham lanzaban desde la obra colectiva Spanish Cultural Studies en 1996. Como en el caso de Richmond, Graham señalaba la discrepancia entre el mensaje y el comportamiento de los altos cuadros de la SF, a los que la segunda describía como conscientes de la libertad relativa que la implicación en la organización les podría reportar. Sin embargo, Graham no se quedaba en esta afirmación y, dando un nuevo uso a la noción de agencia, aseguraba que las ambigüedades y las contradicciones en la praxis de la SF contribuyeron a crear una nueva mentalidad para algunas de las jóvenes de las clases medias y bajas. En definitiva, la autora sostenía que los objetivos políticos conscientes apoyados por la organización

19 La única excepción a este respecto es la mención (siquiera extensa) a la implicación de Mercedes Formica a partir de 1950 en los debates sobre el trabajo femenino: Richmond, 2003, p. 172. Esta ausencia de referencia sobre la participación activa de otras dirigentes es aún más de lamentar si se tiene en cuenta que trabajos como el de Richmond son algunos de los últimos que pudieron contar con fuentes orales, ya perdidas para la generación actual de investigadores. 
podrían ser considerados menos significativos si se tenía en cuenta lo que la organización finalmente aportó al proceso de cambio del régimen del que formaba parte. ${ }^{20}$

Esta afirmación de Graham sintetizaba en buena medida el nuevo modelo de compresión del papel de la SF dentro del régimen que la historiografía ha desarrollado hasta la actualidad. $\mathrm{Si}$, como se ha venido señalando, las investigaciones precedentes habían demostrado que el papel de las élites de mujeres falangistas no se asimiló al modelo que ellas mismas difundían de sumisión, sino que respondía, más bien, a la representación de una identidad fuerte y hábilmente construida a partir del «estilo de la $\mathrm{SF}$ », con Richmond, y sobre todo con la afirmación lanzada por Graham, comenzaría a desarrollarse la imagen de las falangistas como impulsoras también de una mejora de la situación de las mujeres españolas. Es decir, de un paradigma explicativo que leyó a la organización como un brazo sumiso a las jerarquías masculinas y, a través de ella, a todo el aparato estatal, se habría pasado, en el transcurso de veinte años de investigaciones, a considerar el papel activo de aquella misma organización como promotora de un mínimo - o amplio según qué autor - grado de emancipación de la población femenina.

Lógicamente, los matices varían según los trabajos porque en cada uno la lectura sobre la lucha por la emancipación liderada por la SF ha adquirido unos tintes diferentes. Buen ejemplo de ello es el estudio de Rosario Ruiz Franco ¿Eternas menores? Las mujeres en el franquismo, publicado en 2007, fruto de su tesis doctoral leída en 2002. ${ }^{21}$ Aunque centrada en el ámbito jurídico, esta investigación ha supuesto una aportación clave para el debate acerca de las tensiones entre inmovilismo y modernización que sufrió la organización a partir de los años cincuenta. Su autora, en lugar de analizar la SF como un todo homogéneo en el que no cupieran puntos de vista o demandas particulares, reparaba en las trayectorias concretas de tres mujeres: Mercedes Formica, Belén Landáburu y María Telo. Las dos primeras, licenciadas en Derecho, habían tenido una vinculación estrecha con la SF (Formica a través del SEU y como directora del semanario Medina, y Landáburu mediante su colaboración con su Asesoría Jurídica) y ambas habían intervenido a favor de un reconocimiento jurídico más justo e igualitario para las mujeres. La clave de esta actuación, aparte

20 Graham, 1995, p. 193.

21 Ruiz Franco, 2007. 
de los sucesivos y muy peleados logros legislativos que consiguieron y que Ruiz Franco desmenuzaba en su trabajo, residió en que no estuvieron amparadas por el manto de institucionalidad que les habría dado el proceder bajo la cobertura de la SF, sino que fueron apuestas individuales y arriesgadas que, en el caso de ser compartidas con un colectivo femenino, tuvieron que realizarse en el seno de organizaciones al margen de la SF. Otra cosa fue, como Ruiz Franco afirmaba, que el núcleo duro del falangismo femenino, después de haber ignorado - si no boicoteado- las propuestas reformistas, tratara de presentarse a posteriori como «la imagen y las presuntas patrocinadoras de la aprobación de esas reformas jurídicas» cuando el estado de opinión del país constataba y denunciaba la situación anacrónica de la legislación vigente. ${ }^{22}$ Así, las trayectorias recogidas en la investigación de Ruiz Franco probaban la existencia de luchadoras solitarias que, aún en la órbita de la SF, se vieron en la obligación de ir a contracorriente de sus propias compañeras de organización, que aparte de retóricas declaraciones de intenciones, pocos esfuerzos habían dedicado a mejorar la posición legal de las mujeres españolas.

El punto de vista de Inbal Ofer es sustancialmente distinto. En Señoritas in Blue. The making of a female political elite in Franco's Spain. The National Leadership of the Sección Femenina de la Falange (1936-1977), publicado en 2010 y también basado en su tesis doctoral, Ofer retomaba la idea de que la SF no solo no había actuado como subyugadora de las mujeres, sino que había sido la impulsora de toda una cadena de transformaciones legales y sociales en beneficio de la población femenina. ${ }^{23} \mathrm{La}$ piedra angular de su tesis ha sido la defensa de que la élite política femenina de la organización (dentro de la cual reconoce a dos generaciones de mujeres) fue la que puso todos sus esfuerzos por lograr, primero, un lugar de peso e influencia dentro de las «familias del régimen» desde donde poder maniobrar para cumplir con su agenda política y social. En segundo lugar, una vez que esta élite había conseguido tal capacidad de agencia, se encargó de poner en marcha un proyecto de promoción de las mujeres españolas, impulsando su autonomía y luchando contra las facciones más conservadoras del régimen para dotar a la población femenina de derechos laborales y de respaldo legal para que pudiera participar en la vida pública. De este modo, Ofer trataba de resolver el conflicto identitario y

22 Ruiz Franco, 2007, p. 232.

23 Ofer, 2010. 
discursivo de la SF desde la negación (o la minusvaloración) del papel de la organización como instrumento de sumisión y adoctrinamiento de las mujeres españolas. En contraposición a estas tesis clásicas que, como se ha señalado más arriba, fueron las defendidas por investigadoras como Gallego Méndez o Barrachina, Ofer proponía una lectura de la organización como «feminista»e incluso «campeona de los derechos de la mujer en el Franquismo». ${ }^{24}$

Con una orientación bien distinta, el amplio trabajo de Sofía Rodríguez López, que cubre desde estudios locales (más abajo reseñados) hasta reflexiones historiográficas acerca de la investigación sobre la SF, ha puesto de manifiesto recientemente que, junto con estas líneas interpretativas de autoras como Graham y Ofer, las ideas de aquellas investigadoras de la década de los ochenta y noventa continúan estando en vigor como instrumentos de análisis. En su artículo «La Sección Femenina, la imagen del poder y el discurso de la diferencia», la autora ha contrapuesto indirectamente la aparentemente amplia capacidad de agencia política de los mandos femeninos a la - según Rodríguez López - poca autoridad que las élites masculinas reconocían a las falangistas: «siempre fueron ninguneadas en los presupuestos del Estado y del Movimiento. Algo que dejaba patente la escasa trascendencia concedida a la labor política, social y educativa desempeñada, tanto por la Sección Femenina como por [...] el Frente de Juventudes». Y no acababan aquí las distancias entre posiciones historiográficas: en línea con la visión de Coca Hernando sobre la influencia de las transformaciones sociales de finales de los años cincuenta y sesenta sobre el proyecto de mujer que la organización había impulsado, Rodríguez López ha defendido que fue ya en estas fechas cuando la Sección Femenina quiso aprovechar «el tirón de $s u$ diferencia»: «cuando los postulados de la liberalización económica y la apertura internacional demandaban una imagen moderna del país, las falangistas se ocuparon de hacer de esa identidad una bandera reivindicativa frente al anacronismo en que vivían las españolas, [y de] aparecer como abanderadas de esa libertad». 25

Por tanto, el debate sigue abierto en la actualidad. Lejos de haber acuerdo respecto a la lectura que debe hacerse de la organización falangista femenina, existe una fructífera discusión que, a pesar de no llegar

${ }^{24}$ La expresión empleada fue «champion of women's rights within the Francoist political system», Ofer, 2010, p. 18.

${ }_{25}$ Rodríguez López, 2010, pp. 233-257, 243, 251 y 252. 
a acuerdos unánimes sobre las respuestas, sí ha dado lugar a una cierta convergencia en las preguntas. Ángela Cenarro resumía en tres puntos las líneas de estudio que continúan siendo objeto de revisión historiográfica. En primer lugar, señalaba la investigación sobre la capacidad de las mujeres falangistas para crear un espacio propiamente femenino dentro de su cultura política, viril y masculinizante por definición, y sobre las estrategias discursivas y fácticas que emplearon para ello. Por otra parte, apuntaba la necesidad de continuar analizando la contradicción que existió entre el mensaje y la práctica de la SF. Como recuerda la autora, «uno de los aspectos más llamativos de las falangistas era que, si bien fueron portadoras de un discurso (especialmente a partir de 1939) que perseguía la materialización del ideal de esposa y madre, en la práctica cotidiana estuvieron muy lejos de encarnarlo». Finalmente, recomendaba la introducción de una tercera línea que tuviera por objeto la revisión del monolitismo que generalmente se presupone a la SF. De este modo, se podrían plantear estudios acerca de las transformaciones que tuvo que afrontar la organización a lo largo de las distintas de la dictadura; igualmente, sería necesario indagar acerca del grado de pluralidad que existió en las filas de la SF en lo relativo a la elaboración de proyectos políticos y sociales, y a la difusión de modelos de feminidad. Según declaraba Cenarro, apenas conocemos algunos datos sobre las mujeres de la Falange, a excepción de algunos casos más estudiados en los últimos años. Por eso, «a pesar de los avances, sigue siendo muy escasa la información que tenemos sobre aquellas que ocuparon posiciones relevantes dentro de la Sección Femenina o pudieron escalar en el aparato de poder franquista». ${ }^{26}$

Todas estas cuestiones conforman el telón de fondo más o menos homogéneo sobre el que durante las últimas décadas han ido apareciendo también otro tipo de aportaciones que, desde enfoques muy diversos, ofrecen respuestas a las cuestiones lanzadas por los estudios más generales. Por ello, las siguientes páginas se ocuparán de trazar una cartografía somera de este panorama historiográfico identificado las líneas de estudio principales a las que se han adscrito los estudios dedicados a la SF. Antes de atender a ello, es importante advertir que la relación de trabajos que se reseñan más abajo es desigual y con toda certeza no hace justicia a la riqueza de planteamientos que muchos de ellos emplean. Por ello, que se

${ }^{26}$ Cenarro, 2011, pp. 235-240. 
encuentren aquí adscritos a una corriente historiográfica no implica que su contenido no transcienda los límites canónicos de aquella; solo indica que es plausible considerar a tal estudio como representativo, o relevante, para comprender cómo el falangismo femenino ha sido trabajado desde cierta posición teórica.

\section{La SF desde otras perspectivas: individuos y territorios}

El alto número de publicaciones aparecidas en los últimos años ha puesto en evidencia que el análisis historiográfico local y regional es uno de los campos de investigación más prolífico para el estudio de la SF. Los trabajos desarrollados en esta dirección han estado motivados por el propósito de indagar en los procesos sociales y culturales vinculados al falangismo en su realidad concreta. Por ello mismo, sus enfoques no han dejado de producir una suerte de territorialización de la cuestión en estudios que, aunque mayoritariamente han sabido vincular sus conclusiones a un ámbito teórico y temático más amplio, en algunas ocasiones solo han aportado conclusiones yuxtapuestas que contribuyen con nuevos datos, pero que no resuelven ni generan nuevos interrogantes. ${ }^{27}$

En términos generales, las publicaciones realizadas bajo un enfoque local o regional han tratado de explicar la implantación de la SF a estos niveles, destacando la labor de sus mandos, las actividades que pudieron realizar con la población urbana o rural, y las circunstancias concretas que determinaron el éxito o el fracaso de los proyectos de la organización femenina en tales contextos. Así, en un buen número de obras se analiza cuál fue la recepción de planes tan centralizados y homogeneizadores como los de SF en una España rural y provinciana de posguerra, donde el estilo falangista y el modo oficial de hacer política eran bastante menos efectivos que el trato informal y la búsqueda de complicidades para llevar los propósitos políticos a buen puerto. No obstante, los estudios dedicados a las singularidades y peripecias de la organización en un lugar concreto, los que podrían englobarse bajo la fórmula «La SF en», constituyen el grupo más numeroso, seguido de aquellos que, aún conservando la perspectiva regional o local, han preferido incidir en un aspecto concreto de la labor de la SF en una zona determinada.

27 Una reflexión ya apuntada en Rodríguez López, 2010, p. 22. 
En este marco, merecen una mención especial estudios como el Enrique Bengochea Tirado, que aplicando de forma pionera la perspectiva poscolonial al estudio de la SF ha analizado el impacto que el discurso y las actividades de la organización femenina tuvieron en la formación de las mujeres del Sáhara español desde los años sesenta. ${ }^{28}$ Este trabajo, junto con otros como el de Sofía Rodríguez López sobre Almería, constituyen un buen ejemplo de los logros alcanzados por estudios regionales o locales que aportan explicaciones generales al tiempo que ofrecen algo más allá de una visión territorialista. ${ }^{29}$ En El patio de la cárcel, Rodríguez López ha realizado un estudio de la evolución completa de la SF, desde la captación de las mujeres católicas hasta la readaptación de las falangistas a las instituciones democráticas del Estado, lo cual le ha permitido caracterizar las distintas etapas «vitales de la organización» y su correspondencia, o ausencia de ella, con la periodicidad general establecida para la dictadura. Además, tal y como exponía la autora, esta investigación tuvo como objetivo la confrontación de la historia institucional con la visión «desde abajo». Para ello, empleó un gran número de testimonios orales que funcionaron como fuentes privilegiadas para la comprensión de las casuísticas locales.

Siguiendo esta línea, la tesis doctoral leída por María Beatriz Delgado Bueno en 2009, La Sección Femenina en Salamanca y Valladolid durante la Guerra Civil. Alianzas y Rivalidades, establecía un límite cronológico bastante más limitado que el de la obra anterior que, sin embargo, le valía a la autora para profundizar en el análisis comparado de las Delegaciones provinciales de Salamanca y de Valladolid como modelos de funcionamiento de la organización. ${ }^{30}$ El enfoque institucionalista de este trabajo ha dado lugar a la inclusión de otra perspectiva que dialogaba con la local y que, de hecho, la enriquecía enormemente: la transnacional. Así, el estudio incluía dos capítulos en los que se ponía en relación a la organización falangista femenina con los movimientos fascistas europeos por medio de la propaganda que estos generaron y de los viajes que se produjeron para el establecimiento de contacto entre unos y otros.

La insistencia de Delgado Bueno en el estudio comparado transnacional era, aunque breve, una de las pocas excepciones hechas frente a la carencia de aportaciones desde esta perspectiva. Si bien las relaciones his-

\footnotetext{
${ }^{28}$ Bengochea Tirado, 2019.

29 Rodríguez López, 2010.

30 Delgado Bueno, 2009.
} 
pano-germanas, hispano-italianas e hispano-portuguesas cuentan con un amplio número de obras que se encargan de su estudio, las investigaciones centradas en el ala femenina de Falange y sus contactos con las organizaciones coetáneas de su misma naturaleza han escaseado hasta fechas muy recientes. Esta ausencia no puede ser atribuida a la falta de conocimiento de estos vínculos, puesto que desde temprano distintas publicaciones comenzaron a poner de manifiesto su manejo de datos sobre aquellos intercambios entre las organizaciones femeninas. Desde la precoz mención de Isidre Vicuña sobre la correspondencia entre las falangistas españolas y la organización nacionalsocialista alemana, ${ }^{31}$ las referencias a las relaciones entre la SF y la Nationalsozialistische Frauenschaft, los Fasci Femminili y la Mocidade Portuguesa Feminina se han sucedido en investigaciones acerca de la organización española, si bien concediendo una importancia mayor a las alemanas e italianas, muy en detrimento de los estudios sobre la portuguesa, solo recientemente explorada por Irene Flunser Pimentel en «La Mocidade Portuguesa Feminina y la Sección Femenina de la Falange Española. Un análisis comparativo». ${ }^{32}$

Así ocurría en los estudios pioneros sobre la SF que realizaron Gallego Méndez, Barrachina o Sánchez López, donde se documentaban las visitas entre comitivas españolas, alemanas e italianas a partir del material hemerográfico, pero no se ahondaba en los símiles y diferencias que pudieran existir entre unos ejemplos y otros. Justamente por ello, el artículo «Mujer, franquismo, fascismo. La clausura forzada en un «mundo pequeño»» de Carme Molinero sentó un precedente para los estudios comparativos posteriores, ya que ponía en correlación las políticas antifeministas de los regímenes italiano y alemán. ${ }^{33}$ Las historiadoras de la siguiente generación, como Richmond, profundizaron en el valor cultural y social de los contactos entre estos países y continuaron apuntando algunas de las líneas sobre las que debería discurrir el estudio comparado entre estos grupos. En este sentido, trabajos como el de María Luz Blanco Camblor, «Similitudes y diferencias entre la «Sección Femenina» en España y la «Bund Deutscher Mädel» en la Alemania del Tercer Reich. Una aproximación», trataron de sistematizar los paralelismos y desencuentros entre las organizaciones femeninas alemanas y españolas de un manera eficaz, dado su esquematismo, aunque poco precisa y algo generalista en

\footnotetext{
31 Isidre Vicuña, 1976.

32 Flunser, 2018.

33 Molinero, 1998.
} 
algunas cuestiones. De cualquier manera, cabe valorar muy positivamente la breve mención final que Blanco Camblor realizaba acerca de las semejanzas que parecían existir entre los perfiles de las dirigentes falangista y nazi, Pilar Primo de Rivera y Jutta Jüdiger, sugiriendo con ello una vía de análisis comparado que hasta la fecha no ha sido transitada. ${ }^{34}$

A partir de estas aproximaciones, y a buen seguro gracias a ellas, la perspectiva transnacional comenzaría a verse como un instrumento imprescindible para la comprensión de determinados proyectos o de aspectos concretos del falangismo femenino. Así se pondría de manifiesto en las investigaciones sobre objetos tan diversos - y sin embargo conectados - como el Auxilio Social y los Coros y Danzas de la SF. El estudio de Ángela Cenarro sobre la primera de estas cuestiones, La sonrisa de Falange: Auxilio Social en la guerra civil y en la posguerra, es hoy la referencia principal para el debate acerca de la labor asistencial de esta organización, primero rival y posteriormente parte (en tanto que Servicio Social) de la SF. ${ }^{35}$ En sus páginas ha quedado patente la deuda que el Auxilio Social contrajo con el modelo asistencial nazi, admirado e importado por los dirigentes de la organización falangista, así como la presencia de algunas características del Dopolavoro italiano y el Fraft durch Freude alemán en los proyectos asistenciales españoles. Bien es verdad que el estudio de Cenarro había contado con el precedente de El Auxilio Social (1936-1940). La etapa fundacional y los primeros años, de Mónica Orduña Prada, un trabajo en el que ya se había esclarecido el protagonismo de los falangistas promotores del proyecto y en el que se había analizado con detenimiento la estructura asistencial de Auxilio Social y de su creación más polémica y duradera, el Servicio Social. ${ }^{36}$

Por otro lado, partiendo de nuevo de un aspecto concreto del falangismo femenino, Beatriz Martínez del Fresno analizaba en su trabajo

${ }^{34}$ Blanco Camblor, 2005. Uno de los factores que más peso ha tenido en el desarrollo de estas líneas de investigación ha sido el incremento de la producción historiográfica acerca de las políticas femeninas en los regímenes alemán, italiano y portugués. Indudablemente, investigaciones como las de Claudia Koonz (1987), Victoria de Grazia (1992) o la ya citada Irene Flunser Pimentel (2007) han contribuido determinantemente a la proliferación de capítulos y obras completas sobre los vínculos transnacionales. En otra línea, estudios como el Wayne Bowen (2000) han funcionado como verdaderos revulsivos y deben ser considerados hoy como precedentes, no solo de las comparaciones entre la Nationalsozialistische Frauenschaft y la SF, sino de muchas de las investigaciones actuales sobre esta última.

35 Cenarro, 2005.

36 Orduña Prada, 1996. 
«La Sección Femenina de Falange y sus relaciones con los países amigos. Música, danza y política exterior durante la guerra y el primer franquismo (1937-1943)» el cariz diplomático que adquirieron estas actividades culturales de la SF. ${ }^{37}$ Aunque en este caso también existía un estudio monográfico previo sobre esta faceta de la SF, La España que bailó con Franco: coros y danzas de la Sección Femenina, de Estrella Casero, el artículo de Martínez del Fresno destaca porque no solo se ocupaba de las influencias germanas e italianas sobre los proyectos folclórico-diplomáticos, sino que también analizaba de qué modo los viajes realizados por los Coros y Danzas contribuyeron a que la dictadura restableciera o afianzara sus vínculos internacionales con otros estados del entorno europeo o de Latinoamérica. ${ }^{38}$

De cualquier forma, el caso más claro de la relevancia que ha cobrado la perspectiva transnacional para la interpretación historiográfica de la SF es la tesis doctoral de Toni Morant i Ariño, Mujeres para una «Nueva Europa». Las relaciones y visitas entre la Sección Femenina de Falange y las organizaciones femeninas nazis, 1939-1945. ${ }^{39}$ Como su título indica, este trabajo ha acometido el estudio de las relaciones entre ambos proyectos a partir de las mutuas visitas y los contactos que establecieron entre 1936 y el final de la Segunda Guerra Mundial. Así, en sentido cronológico, su autor ha revisado estos intercambios partiendo del temprano establecimiento de las relaciones en 1936-1937, pasando por las primeras visitas de estudio y el esplendor de estas mismas en 1941 y 1942, hasta el fin de los contactos hacia 1945.

\section{Biografías falangistas}

En otro orden de cosas, las trayectorias vitales de las mujeres de SF conforman un campo de investigación para el estudio de la cultura política falangista apenas inaugurado. Como ha ocurrido en otros tantos ámbitos de la historiografía, la aplicación de la historia biográfica a las vidas de estas mujeres comenzó a dar sus frutos en formas de biografía muy sujetas a los cánones clásicos del género, modelos que ya se saben en parte superados, pero que siguen muy presentes en estudios que tratan de cen-

\footnotetext{
37 Martínez del Fresno, 2010.

38 Casero, 2000.

39 Morant, 2013.
} 
trarse más en la descripción de perfiles que en el tratamiento de los problemas históricos a los que una vida está vinculada. Lógicamente, esta generalidad no se refiere a todos los trabajos, ni representa a aquellos que ya han comenzado a ahondar en la creación de identidades falangistas entre las mujeres, pero sí caracteriza cierta tónica general persistente en bastantes de las obras que se van a reseñar.

Este primer problema parece muy relacionado con otro de los déficits de la historia biográfica de las falangistas. Como han señalado Susana Tavera y Ángela Cenarro, apenas abundan las biografías dedicadas a otras figuras que no sea la de Pilar Primo de Rivera, la falangista políticamente más visible de la organización. En consecuencia, existe un desconocimiento prácticamente total acerca del perfil social, familiar y político de las mujeres que ocuparon los rasgos inferiores de la organización. Y así, «a pesar de los avances, sigue siendo muy escasa la información que tenemos sobre aquellas que ocuparon posiciones relevantes dentro de la Sección Femenina o pudieron escalar en el aparato de poder franquista». ${ }^{40}$ Ciertamente, a Pilar Primo de Rivera solo le sigue en atención historiográfica Mercedes Formica, también «camisa vieja» de trayectoria no tan representativa del falangismo femenino y muy probablemente por ello uno de los casos más habituales de estudio. A este respecto, es oportuno señalar que las dos mujeres cuyas vidas han sido más traídas a colación en los estudios sobre las falangistas habían dejado sendas memorias/autobiografías escritas que con el tiempo se convirtieron en piezas indispensables para la comprensión de sus trayectorias y cuya utilización, si bien del todo lícita y generalmente provechosa, también ha viciado en algunos casos la visión sobre ellas. Por este motivo, en el recorrido que a continuación se va a trazar se han incluido también las reseñas de aquellas obras de la literatura del yo que han nutrido de distintas maneras las investigaciones sobre las falangistas y en parte también explican algunas de las conclusiones a las que estas han conducido.

El primer trabajo que abordó el estudio conjunto de varias trayectorias y que incluyó la de una falangista fue Palomas de guerra. Cinco mujeres marcadas por el enfrentamiento bélico, de Paul Preston. En esta amplia

40 Ángela Cenarro, 2011 p. 240; Tavera, 2011, p. 209. Es importante subrayar la atención que la primera ha dedicado tanto a Mercedes Sanz Bachiller - probablemente la tercera figura mejor conocida tras Primo de Rivera y Formica- como a Carmen de Icaza, mucho menos estudiada, pero no por ello menos relevante para el falangismo femenino. Cenarro, 2005, 2000. 
obra el autor dedicó un capítulo extenso a Mercedes Sanz Bachiller en el que se explicitaba de qué manera durante la guerra civil y los primeros años de franquismo la vida personal de Sanz Bachiller se entrelazó con algunos acontecimientos políticos fundamentales para Falange. ${ }^{41}$ Para comprender este trabajo sobre biografías plurales es importante no perder de vista que la intención de Preston tuvo más que ver con la confección de densos y bien documentados perfiles de mujeres testigos y agentes en la guerra civil, que con la elaboración de conclusiones que arrojaran luz sobre la conformación de identidades durante estos años. Su afirmación, a la altura de un breve epílogo final, sobre cómo desde la excepcionalidad de las vidas que aborda se pueden entender mejor «los estragos emocionales ocasionados por la guerra civil española», resultaba demasiado escasa desde el punto de vista de la historia biográfica, aunque también permitía tomar este estudio como punto de partida para indagar nuevos modos de lectura de las vidas que Preston había reunido. ${ }^{42}$

En una línea parecida a la de Palomas de guerra, algunas obras escritas a partir del cambio de siglo empezaron a integrar reseñas biográficas de mujeres falangistas entre las voces femeninas del franquismo que se pretendían recuperar. Tal fue el caso de Mujeres de la postguerra. De Carmen Laforet a Rosa Chacel: historia de una generación de Inmaculada de la Fuente, donde se incluía un capítulo sobre Mercedes Formica documentado principalmente a través de la autobiografía de esta última. Pocos años después, la misma autora publicaba un estudio biográfico doble de las hermanas María (Marichu) y Constancia de la Mora, titulado La roja y la falangista. Dos hermanas en la España del 36, en el que se revisaban las trayectorias confrontadas de ambas, la primera alto mando de la SF y muy cercana al círculo de José Antonio Primo de Rivera, y la segunda militante e importante cargo del Partido Comunista exiliada en México. ${ }^{43}$ Más recientemente, Soraya Gahete Muñoz ha explorado la figura de otra falangista, Dora Maqueda, Secretaria General de la SF en sus primeros años. ${ }^{44}$ A diferencia de lo que ocurrió con la antes citada María de la Mora, Maqueda no llegó a la SF por medio de su vinculación al grupo intelectual del líder falangista, ni siquiera por cercanía personal a Pilar Primo de Rivera, sino por una motivación eminentemente política,

\footnotetext{
41 Preston, 2001.

42 Preston, 2001, p. 429.

43 De la Fuente, 2002, 2006.

44 Gahete Muñoz, 2015.
} 
dado su anterior compromiso con el Partido Nacionalista Español. Un caso parecido al de Rosario Pereda que, como bien ha mostrado Christine Lavail, militó en las JONS antes de la unificación de estas con Falange Española y tuvo un papel más que destacado (y excepcional, para Lavail) en la actividad propagandística del partido nacido en $1933 .{ }^{45} \mathrm{De}$ esta forma, la confrontación de los estudios sobre María de la Mora, Dora Maqueda y Rosario Pereda pone de manifiesto indirectamente una de las líneas de investigación en las que seguir abundando en el marco de la historia biográfica dedicada a falangistas de SF: la de las motivaciones que animaron a aquellas primeras mujeres a integrarse en el naciente movimiento nacionalsindicalista durante los años republicanos.

Según se adelantaba más arriba, la publicación de memorias o autobiografías de mujeres falangistas a partir de los años ochenta ha sido esencial para buena parte de las investigaciones que se han desarrollado sobre la SF, Auxilio Social u otros proyectos políticos en los que la rama femenina de Falange se vio envuelta. La primera en sacar a la luz sus recuerdos fue Mercedes Formica, que publicó tres entregas sucesivas del relato de su vida tituladas Visto y vivido, Escucho el silencio y Espejo roto y espejuelos. ${ }^{46}$ Estas tres obras conjugaban la narración de acontecimientos cercanos, familiares y cotidianos con una reflexión sobre los hechos políticos de la dictadura, lo que servía a Formica para reafirmar su respaldo al falangismo auténtico, según ella encarnado en el primer círculo en torno a José Antonio, cuya «esencia» comenzó a diluirse a partir de la entrada de «advenedizos» al inicio de la guerra. Por otro lado, la autora trataba de dejar constancia tanto de su lucha por que las mujeres alcanzasen las mismas oportunidades laborales que los hombres en el terreno de la judicatura, como de sus esfuerzos por promover la mejora de la situación legal de las españolas desde su propio trabajo de abogada y en tanto que miembro de la SF. Estas características de su escritura han hecho de la extensa autobiografía de Formica una fuente esencial - junto con sus artículos periodísticos y sus novelas - para los estudios dedicados a su figura. Entre ellos, y sin ánimo de exhaustividad, cabe destacar las obras de Rosario Ruiz Franco, que ha trabajado tanto su perfil biográfico como su relevancia en el proceso de cambio legislativo que condujo a la promulgación de la Ley sobre Derechos Políticos, Profesionales y de Trabajo de la Mujer

\footnotetext{
45 Lavail, 2008.

46 Formica, 1982, 1984, 1988.
} 
de 1961; así como las aportaciones de Miguel Soler, mucho más enfocadas al estudio de su narrativa, y de María Cristina Lorenzo Rodríguez, dirigidas a la recuperación y homenaje de su memoria. ${ }^{47}$

En cualquier caso, la falangista con un perfil político y personal más estudiado ha sido Pilar Primo de Rivera, Delegada Nacional de SF y desde 1937 hasta su muerte en 1991 representante para un amplio sector del régimen del falangismo «joseantoniano» o «auténtico». La propia Primo de Rivera fue la primera en considerar la importancia que el relato que su vida tendría para la valoración de su obra una vez esta fuera desmantelada en $1977 .{ }^{48}$ En una fecha bastante elocuente, 1983 (mismo año en que aparecía el estudio de Gallego Méndez), Pilar Primo de Rivera publicaba sus memorias Recuerdos de una vida, prologadas en forma de glosa por Eugenio d'Ors, en las que un afán de autojustificación apenas disimulado se mezclaba con un propósito reafirmador de su identidad como personaje político. Por ello, no resulta extraño que, aparte de los tres primeros capítulos en los que fue prolija en referencias a su entorno familiar, el resto de la obra (veintisiete capítulos) estuviera centrado en la narración de las vicisitudes políticas vividas por los falangistas y la SF hasta la llegada de la democracia. En consecuencia, tanto el contenido del relato como la voluntad redentora que impulsó su escritura han convertido a las memorias de Pilar Primo de Rivera en un documento imprescindible no solo para analizar el prisma desde el que ella interpretó la evolución política del régimen (siempre considerando que se trataba de una lectura retrospectiva), sino también para comprender cómo operaron los agentes históricos que en los años de la Transición, y ante la angustia del futuro que suponía para ellos el nuevo sistema, optaron por trabajar en la reconfiguración de la memoria colectiva por medio de la suya propia.

Buen ejemplo de esto último es el trabajo de Inbal Ofer, que ha abordado el estudio de las memorias de Pilar Primo de Rivera en su trabajo «Fragmented Autobiographies: a Style of Writing or Self-Perception? The Case of Pilar Primo de Rivera». ${ }^{49}$ Empleando categorías propias del análisis de la llamada «escritura del yo» y reivindicando la validez del cruce de la perspectiva de género con el estudio de las condiciones socioculturales de quien escribe, Ofer ha defendido que el relato que la Delegada Nacional de la SF presenta una serie de «rupturas» 0 «contradicciones» dis-

\footnotetext{
47 Ruiz Franco, 1997, 2007; Soler Gallo, 2010; Lorenzo Rodríguez, 2005.

48 Primo de Rivera, 1983.

49 Ofer, 2003, pp. 37-51.
} 
cursivas que reflejan el modo en que ella valora su historia al frente de la organización falangista. Así, el empleo de fórmulas gramaticales impersonales sería, para Ofer, una estrategia para desvincularse o minimizar su relación con ciertos acontecimientos «puramente políticos», mientras que el recurso a la primera persona en relación a otros eventos, principalmente aquellos que tienen que ver con «la promoción» de los derechos de la mujer por parte de la SF, señalaría su intención de remarcar su acción en circunstancias que pudieran ser vistas con ojos favorables en el contexto de la temprana democracia.

Por otra parte, el perfil político de Pilar Primo de Rivera, su trayectoria al mando de la SF y su vida personal también han sido motivo de libros y artículos que a partir del cambio de siglo han tratado de demostrar las distintas facetas de la dirigente política y que, como ya hiciera Ofer, también se han valido de las memorias de la Delegada Nacional de SF. En este sentido, la tesis doctoral de Karine Bergès, Pilar Primo de Rivera (1906-1991). Cause féminine, idéologie phalangiste, stratégies et enjeux politiques dans l'ombre du régime franquiste, supuso un auténtico revulsivo para la evolución de los estudios sobre la figura de la Delegada Nacional y de la élite de la organización falangista femenina, ya que dedicaba un apartado específico a abordar el análisis crítico de sus memorias y las dificultades que la falangista tuvo para tomar distancia de los hechos que había vivido y estaba narrando, además de analizar desde el punto de vista de la Delegada Nacional - y no desde la organización en conjunto, como antes se había hecho - el culto a la figura de José Antonio y los conflictos abiertos con otros grupos de poder del régimen como la Iglesia. ${ }^{50}$

Otro de los fines implícitos a los que parecen dirigirse los trabajos sobre Pilar Primo de Rivera es la caracterización de la SF a partir de su figura, esto es, al empleo de la trayectoria de su Delegada Nacional como instrumento para el análisis de los procesos internos de la organización. Este tipo de enfoques, si bien tienen el beneficio de contribuir al conocimiento de la élite femenina de la SF, no dejan de producir perfiles biográficos muy limitados, que apenas rescatan al individuo que se pueda encontrar más allá de la ocupación política. Así ocurre en el capítulo dedicado por Paul Preston a Pilar Primo de Rivera en Las tres Españas del 36, donde las referencias a su vida personal, con una predilección ya casi clá-

50 Bergès, 2003. 
sica en este tipo de obras por recorrer su infancia, apenas oculta una inclinación a narrar la historia de la SF a través de la trayectoria de Pilar y no tanto a plantear las contradicciones y tensiones internas de un personaje al que casi siempre se resuelve con una semblanza biográfica un tanto plana. ${ }^{51}$

También María Antonia Fernández Jiménez ha estudiado la figura de la jefa falangista en Pilar Primo de Rivera. El falangismo femenino, una biografía que se adapta a los moldes más conservadores del género, en tanto que mantiene su organización cronológica, pero profundiza más que los trabajos antes citados en la formación de la identidad del personaje histórico. ${ }^{52}$ Para ello, Fernández Jiménez ha abordado su labor al frente de la SF sin ceñirse restrictivamente al análisis de esta faceta (aún sabiendo, y siendo consecuente con ello, que gran parte de su vida giró en torno a ella), sino teniendo en cuenta otros momentos de su vida, como su niñez o su senectud durante el principio de la democracia, que ayudan a completar un perfil histórico habitualmente inacabado. En las antípodas de este trabajo se encuentra la propuesta de Antonio Prometeo Moya, que ha concebido su obra Últimas conversaciones con Pilar Primo como una ficción estructurada a modo de diario en el que se recogen las entrevistas realizadas a la jefa falangista a finales de $1990 .{ }^{53}$ Muchas de las cuestiones formuladas por el autor trataban de corroborar las afirmaciones que ella misma había vertido en sus memorias; algunas se dirigían a confrontar hipótesis historiográficas sobre importantes polémicas con su propia opinión (el «caso Hedilla», por ejemplo) y otras tantas buscaban hacer reflexionar a la Delegada Nacional de SF sobre el papel de Falange y su organización durante la dictadura.

De todo lo anterior se puede deducir fácilmente que el perfil de $\mathrm{Pi}$ lar Primo de Rivera es el más estudiado y, hasta cierto punto, el mejor conocido y el que ha contado con mayor diversidad de enfoques en su tratamiento. Pero la atención prestada a la jefa de la Falange femenina también ha provocado el ensombrecimiento de otras figuras de su misma organización. El poco interés que ha suscitado, por ejemplo, el estudio de la vida cotidiana de las mujeres de las bases de la SF (divulgadoras, enfermeras, maestras) se manifiesta en la prácticamente nula atención que han despertado materiales como Las voces del silencio: Memorias de una instructora

\footnotetext{
51 Preston, 2011, pp. 312-396.

52 Fernández Jiménez, 2008.

53 Prometeo Moya, 2006.
} 
de juventudes de la Sección Femenina ${ }^{54}$ Esta obra recoge los recuerdos de María Luisa de León Llorente, quien afirmaba pretender únicamente «especificar la labor desarrollada en tantos aspectos educativos y de tiempo libre por las instructoras de juventudes: unas mujeres que se entregaron - nos entregamos - de buena fe a un ideal y que dedicaron todo su tiempo y esfuerzo a los demás». La voluntad autojustificatoria, que enlaza con las intenciones de otros proyectos biográficos como el de Pilar Primo de Rivera, no solo no resta un ápice de interés al texto, sino que lo convierte en una fuente del todo útil para explicar la construcción de un relato acerca de la labor «benéfica y despolitizada» de las falangistas durante la Transición.

Como estas páginas han procurado mostrar, los avances producidos en el conocimiento del falangismo femenino a lo largo de las últimas décadas son sustanciales. Entre ellos, cabe señalar el extenso recorrido que han tenido observaciones como la de Sánchez López sobre los tres cauces por los que discurrirían las investigaciones acerca de la SF: la profundización en la ideología propia de la organización, el margen de actuación política real que tuvieron las falangistas y la dimensión sociológica de la SF. En buena medida, los tres caminos abrían posibilidades al estudio de la creación de un espacio político y de una identidad propia, fuera monolítica y unidireccional - como se concluía en los primeros estudios de Gallego Méndez - o bien dual - como proponía la diferenciación de Barrachina entre el ideal falangista de la mujer y el ideal de mujer falangista - . Esta segunda vía de indagación posibilitó la proliferación de hipótesis sobre un modelo de mujer falangista que no era tanto el impuesto desde el poder masculino (del partido, del régimen), sino una creación propia y consciente que respondía a la voluntad de diferenciarse como élite política femenina. Es más, sentó un precedente para la línea general a la que se adscriben mayoritariamente las investigaciones actuales sobre el falangismo femenino: el estudio de la agencia de estas mujeres dentro del sistema falangista y franquista.

Buena parte de los investigadores centrados en la problemática de la agencia han puesto su mirada en la cúspide de la organización falangista con el propósito de arrojar luz sobre la pregunta de cómo aquellas mujeres maniobraron para procurarse espacios de acción y una identidad

${ }^{54}$ De León Llorente, 2000. 
propia. En cierta medida, esto ha conllevado una atención prioritaria por parte de la bibliografía hacia las élites de la organización y a su participación en la configuración institucional de la SF, dejando fuera del foco de análisis la acción de aquellas falangistas que, sin ser altas jerarcas, estuvieron al frente de organismos tan vitales para la organización como los consagrados a la formación de las mujeres, principalmente los de prensa y propaganda. Y, sobre todo, ha dejado fuera del radar de la historiografía el significado que la SF fue confeccionando sobre el concepto de feminidad, una idea que se nutrió de materiales que iban más allá de las palabras puntuales del líder del Partido o de la Delegada Nacional porque, aunque se construyera en base a las premisas que estos estipularon, integró también las opiniones y matizaciones de mandos medios o de intelectuales allegados/as a la SF. En consecuencia, la reflexión sobre este discurso institucional y los efectos de su imposición sobre las españolas durante más de cuatro décadas se presenta hoy como un ejercicio historiográfico oportuno y necesario. Una tarea permitiría enlazar con la prolífica genealogía de cuestiones hasta aquí revisada en torno a la coherencia o contradicción entre el discurso y la práctica de la SF.

Para esta tarea no escasearán, desde luego, las opciones metodológicas: desde la ya clásica teoría de género hasta la perspectiva poscolonial, pasando por la historia de las emociones o la historia biográfica, existe un copioso conjunto de posiciones teóricas absolutamente compatibles entre sí que pueden ser tenidas en cuenta en los trabajos que se aventuren al análisis de la SF y de lo que presumiblemente hoy sea una de las cuestiones más atractivas, por significativa para nuestro presente, a enfrentar: la de cómo - por medio de qué instrumentos materiales y valiéndose de qué discurso - la organización trabajó para hacer realidad su tarea de formar a las mujeres españolas en un paradigma compartido de mujer, y de qué manera esta labor aleccionadora influyó tanto en el desarrollo del mismo régimen que la amparaba como en la construcción identitaria de las mujeres tuteladas por las falangistas.

\section{Bibliografía}

BARRACHINA MORÓN, Marie-Aline, La Section Feminine de FET et des JONS puis du Mouvement National. Origines, genèse, influence, fin: 19331977, Thèse de troisième cycle, Université de la Sorbonne Nouvelle Paris III, s.f. [1979]. 
BARRACHINA MORÓN, Marie-Aline, «Ideal de la Mujer Falangista. Ideal Falangista de la Mujer», en VV.AA., Las mujeres y la guerra civil española, Madrid, Ministerio de Trabajo e inmigración, Instituto de la Mujer, 1991.

BLANCO CAMBLOR, María Luz, «Similitudes y diferencias entre la "Sección Femenina" en España y la "Bund Deutscher Mädel” en la Alemania del Tercer Reich. Una aproximación», en SANTO TOMÁs PÉREZ, Magdalena, Vivir siendo mujer a través de la historia, Universidad de Valladolid, Secretariado de Publicaciones e Intercambio Editorial, 2005, pp. 215-240.

BENGOCHEA TIRADO, Enrique, La Sección Femenina en la provincia de Sahara. Entrega, hogar e imperio, Barcelona, Bellaterra, 2019.

BERGÈS, Karine, Pilar Primo de Rivera (1906-1991). Cause féminine, idéologie phalangiste, stratégies et enjeux politiques dans l'ombre du régime franquiste, Tesis Doctoral, Université de Toulouse, 2003.

BLASCO HERRANZ, Inmaculada, Armas femeninas para la contrarrevolución: la Sección Femenina en Aragón (1936-1950), Málaga, Servicio de Publicaciones de la Universidad de Málaga, 1999.

BLASCO HERRANZ, «Las mujeres de la Sección Femenina de Falange: sumisión, poder y autonomía», en SEGURA GRAIIÑO, Cristina y CERRADA JIMÉNEZ, Ana Isabel (coords.), Las mujeres y el poder: representaciones y prácticas de vida, Madrid, Asociación Cultural Al-Mudayna, 2000, pp. 253-268.

BOWEN, Wayne H., Spaniards and Nazi Germany. Collaboration in the New Order, Columbia y Londres, University of Missouri Press, 2000.

CASERO, Estrella, La España que bailó con Franco: coros y danzas de la Sección Femenina, Madrid, Nuevas Estructuras, 2000.

CENARRO, Ángela, «Carmen de Icaza: novela rosa y fascismo», en QUIROGA FERNÁNDEZ DE SOTO, Alejandro y DEL ARCO, Miguel Ángel (eds.), Soldados de Dios y Apóstoles de la Patria. Las derechas españolas en la Europa de entreguerras, Granada, Comares, 2000, pp. 374-396.

CENARRO, Ángela, La sonrisa de Falange. Auxilio Social en la guerra civil y en la posguerra, Barcelona, Crítica, 2005.

CENARRO, Ángela, «Trabajo, maternidad y feminidad en las mujeres del fascismo español» en AGUADO, Ana María; ORTEGA LÓPEZ, Teresa María (coords.), Feminismos y antifeminismos. Culturas políticas e identidades de género en la España del siglo XX, Valencia, Universidad de Valencia, 2011, pp. 229-252.

COCA HERNANDO, Rosario, «Towards a New Image of Women under Franco: The Role of Sección Femenina», International Journal of Iberian Studies, 11, 1998, pp. 5-13.

DE GRAZIA, Victoria, How fascism ruled women: Italy, 1922-1945, University California Press, 1992.

DE LA FUENTE, Inmaculada, Mujeres de la posguerra. De Carmen Laforet a Rosa Chacel: historia de una generación, Barcelona, Planeta, 2002. 
DE LA FUENTE, Inmaculada, La roja y la falangista. Dos hermanas en la España del 36, Barcelona, Planeta, 2006.

DE LEÓN LLORENTE, María Luisa, Las voces del silencio: memorias de una instructora de juventudes de la Sección Femenina, Madrid, Auto-editor, 2000.

DELGADO BUENO, María Beatriz, La Sección Femenina en Salamanca y Valladolid durante la Guerra Civil. Alianzas y Rivalidades, Tesis doctoral, Salamanca, Universidad de Salamanca, 2009.

FERNÁNDEZ JIMÉNEZ, María Antonia, Pilar Primo de Rivera. El falangismo femenino, Madrid, Síntesis, 2008.

FLUNSER PIMENTEL, Irene, Mocidade Portuguesa Feminina, Lisboa, Esfera dos Livros, 2007.

FLUNSER PIMENTEL, Irene, «La Mocidade Portuguesa Feminina y la Sección Femenina de la Falange Española. Un análisis comparativo», Historia del Presente, 32, 2018, pp. 43-56.

FORMICA, Mercedes, Visto y vivido. Pequeña historia de ayer I. 1931-1937, Barcelona, Planeta, 1982.

FORMICA, Mercedes, Escucho el silencio. Pequeña historia de ayer II, Barcelona, Planeta, 1984.

FORMICA, Mercedes, Espejo roto, y espejuelos, Madrid, Huerga \& Fierro, 1988.

GAHETE MUÑOZ, Soraya, «Dora Maqueda. Su militancia en Falange española», Asparkia, 25, 2015, pp. 163-180.

GALLEGO MÉNDEZ, María Teresa, Mujer, Falange y Franquismo, Madrid, Taurus, 1983.

GRAHAM, Helen, «Gender and the State: Women in the 1940s», en LABANYI, Jo y Graham, Helen (eds.), Spanish Cultural Studies. An Introduction. The Struggle for Modernity, Oxford, Oxford University Press, 1995.

KOONZ, Claudia, Mothers in the Fatherland: Women, the Family and Nazi Politics, Nueva York, Martin's Press, 1987.

LAVAIL, Christine, «De la creación de la Sección Femenina (1934) a la campaña electoral de 1936: Modalidades de intervención de las mujeres falangistas en la esfera pública», Arenal, 15:2, 2008, pp: 345-370.

LORÉE ENDERS, Victoria, «Problematic Portraits: The Ambiguous Historical role of the Sección Femenina of the Falange», en LORÉE ENDERS, Victoria y RADCLIFF, Pamela Beth: Constructing Spanish Womanhood. Female identity in Modern Spain, Nueva York, State University of New York Press, 1999, pp. 375-397.

LORÉE ENDERS, Victoria, «Nationalism and Feminism: the Sección Femenina of the Falange», History of European Ideas, vol. 15, 4-6, 1992, pp. 673-680.

LORENZO RODRÍGUEZ, María Cristina, Una gaditana a conocer y reconocer, Cádiz, Fundación Municipal de la Mujer, 2005.

MARTÍNEZ DEL FRESNO, Beatriz, «La Sección Femenina de Falange y sus relaciones con los países amigos. Música, danza y política exterior durante 
la guerra y el primer franquismo (1937-1943)», en PÉREZ ZALDUONDO, Gemma y CABRERA GARCÍA, María Isabel (coords.): Cruces de caminos. Intercambios musicales y artísticos en la Europa de la primera mitad del siglo XX, Granada, Editorial Universitaria de Granada, 2010, pp. 357-406.

MOLINERO, Carme, «Mujer, franquismo, fascismo. La clausura forzada en un “mundo pequeño"», Historia Social, 30, 1998, pp. 97-117.

MORANT Y ARIÑO, Toni, Mujeres para una «Nueva Europa». Las relaciones y visitas entre la Sección Femenina de Falange y las organizaciones femeninas nazis, 1939-1945, Tesis doctoral, Valencia, Universidad de Valencia, 2013.

MORANT Y ARIÑO, Toni, ««Las mujeres que también fueron fascistas». Los primeros años de la Sección Femenina de Falange en una mirada transnacional», Historia del Presente, 32, 2018:2, pp. 11-26.

ORDUÑA PRADA, Mónica, El Auxilio Social (1936-1940). La etapa fundacional y los primeros años, Madrid, Escuela Libre Editorial, 1996.

OFER, Inbal, «Fragmented Autobiographies: a Style of Writing or Self-Perception? The Case of Pilar Primo de Rivera», Iberoamericana, III, 9 (2003), pp. 37-51.

OFER, Inbal, Señoritas in Blue. The making of a female political elite in Franco's Spain. The National Leadership of the Sección Femenina de la Falange (1936-1977), Oxford, Oxford University Press, 2010.

PÉREZ CANTÓ, María Pilar y FOLGUERA, Pilar et al. (coords.), Democracia, Feminismo y Universidad en el siglo XXI, Madrid, Universidad Autónoma de Madrid, IUEM, 2005.

PRESTON, Paul, Palomas de guerra. Cinco mujeres marcadas por el enfrentamiento bélico, Barcelona, Plaza y Janés, 2001.

PRESTON, Paul, Las tres Españas del 36, EspaEbook, edición Epub, edición Epub, 2011.

PRIMO DE RIVERA, Pilar, Recuerdos de una vida, Madrid, Ediciones Drysa, 1983.

PROMETEO MOYA, Antonio, Últimas conversaciones con Pilar Primo, Madrid, Caballo de Troya, 2006.

RICHMOND, Kathleen, The Yoke of Isabella: the Women's Section of the Spanish Falange 1934-1959, PhD Thesis, Southhampton, Universidad de Southhampton, 1999.

RICHMOND, Kathleen, Las mujeres en el fascismo español. La Sección Femenina de la Falange, 1934-1959, Madrid, Alianza, 2003.

RODRÍGUEZ LÓPEZ, Sofía, El patio de la cárcel. La Sección Femenina de FET-JONS en Almería (1937-1977), Sevilla, Centro de Estudios Andaluces, 2010a.

RODRÍGUEZ LÓPEZ, Sofía, «La Sección Femenina, la imagen del poder y el discurso de la diferencia», Feminismo/s. Revista del Instituto de Investi- 
gación de Estudios de Género de la Universidad de Alicante, 16, 2010b, pp. 233-257.

RUIZ FRANCO, Rosario, Mercedes Formica (1916-), Madrid, Ediciones del Orto, Biblioteca de Mujeres, 1997.

RUIZ FRANCO, Rosario, ¿Eternas menores? Las mujeres en el franquismo, Madrid, Biblioteca Nueva, 2007.

SÁNCHEZ LÓPEZ, Rosario, Una sombra de destino en lo universal. Trayectoria histórica de Sección Femenina de Falange (1934-1977), Murcia, Universidad de Murcia, 1990.

SÁNCHEZ LÓPEZ, Rosario, «Sección Femenina, una institución en busca de investigador. Análisis crítico de la bibliografía disponible», Historia Social, 17, 1993, pp. 141-154

SOLER GALLO, Miguel, «La situación jurídica de la mujer en el franquismo: divorcio y adulterio en dos novelas de Mercedes Formica», en ANTÓN PACHECO-BRAVO, Ana et al. (dir.), Estudios de mujeres. Volumen VII: Diferencia, (des)igualdad y justicia, 2010, Madrid, Editorial Fundamentos, pp. 309-321.

TAVERA, Susana, «Las mujeres de la sección de la falange. Una afirmación entre el activismo político y la sumisión patriarcal, 1934-1939», en AGUADO, Ana M. y ORTEGA LÓPEZ, Teresa María, Feminismos y antifeminismos. Culturas políticas e identidades de género en la España del siglo XX, Valencia, Universidad de Valencia, 2011, pp. 207-208.

VICUÑA, Isidre, «Trabajo femenino en la postguerra: la mujer nacionalsindicalista», Dossier Ciudadano, 5, 1976, pp. 69-75.

\section{Datos de la autora}

Begoña Barrera López es Doctora en Historia Contemporánea por la Universidad de Sevilla. Dedica su investigación al estudio del Franquismo desde la perspectiva político-cultural y se interesa por líneas de investigación como la historia de las emociones, la historia biográfica o la teoría de género. Actualmente, es investigadora posdoctoral en el proyecto europeo HERA 200.2 "Beyond Stereotypes: Cultural Exchanges and the Romani Contribution to European Public Spaces» (BESTROM), al que contribuye con una investigación sobre la historia de los intelectuales romaníes europeos. 